\title{
CENTENARY REVIEW
}

\section{Evolutionary plant breeding for low input systems}

\author{
S. L. PHILLIPS AND M. S. WOLFE* \\ Elm Farm Research Centre, Hamstead Marshall, Near Newbury, Berkshire, RG20 0HR, UK
}

(Revised MS received 23 November 2004)

\begin{abstract}
SUMMARY
Heritable variation is at the heart of the process of evolution. However, variation is restricted in breeding for uniform crop populations using the pedigree line approach. Pedigree lines are successful in agriculture because synthetic inputs are used to raise fertility and control weeds, pests and diseases. An alternative method promoted for exploring the value of variation and evolutionary fitness in crops is to create composite cross populations. Composite cross populations are formed by assembling seed stocks with diverse evolutionary origins, recombination of these stocks by hybridization, the bulking of $F_{1}$ progeny, and subsequent natural selection for mass sorting of the progeny in successive natural cropping environments. Composite cross populations can provide dynamic gene pools, which in turn provide a means of conserving germplasm resources: they can also allow selection of heterogeneous crop varieties. The value of composite cross populations in achieving these aims is dependent on the outcome of mass trials by artificial and natural selection acting upon the heterogeneous mixture. There is evidence to suggest that composite cross populations may be an efficient way of providing heterogeneous crops and of selecting superior pure lines for low input systems characterized by unpredictable stress conditions.
\end{abstract}

\section{INTRODUCTION}

There has been no greater contribution to our understanding of the origin of life, the organization of the natural world and the progression of species, than Darwin's (1859) description of evolution. Darwin proposed a mechanism for the process of evolution that he termed natural selection, suggesting that a population of organisms can change over time as a result of individuals with certain heritable traits leaving more offspring than other individuals. Thus heritable variation is at the heart of the process of evolution, with the sources of this variation being mutation and sexual recombination. The theory of natural selection thereby recognizes that evolutionary change is based upon interactions between the environment and populations containing individuals demonstrating heritable variation for traits, where the environmental interactions are both abiotic and biotic.

The pedigree line breeding approach in self-fertile crop plants adopts artificial selection in which the

* To whom all correspondence should be addressed. Email:martin@wakelyns.demon.co.uk 'best' parents are used while others are discarded, truncating the potential for any selection response. As a result, variability is limited both within genotypes (phenotypic plasticity) and among genotypes (genetic variability) in the pursuit of the notion that strictly uniform crop populations are a universal ideal (Simmonds 1962).

This approach received a major boost from two papers published 100 years ago (Biffen 1905; Butler 1905) in the Journal of Agricultural Science, Cambridge. Indeed, it was Sir Rowland Biffen who introduced Mendelian genetics into wheat breeding, became the first Director of the Plant Breeding Institute at Cambridge in 1912 and led the development of pedigree line breeding in self-pollinating cereals.

Pedigree line breeding remained dominant throughout the twentieth Century largely because its further development went hand-in-hand with the development of high input production, particularly in the second half of the century. In recent years, the range and scale of inputs used has been sufficient to limit drastically the natural variation to which crops are exposed and thus the need for extensive genetic variation in the crops involved. 
Uniform crop populations are convenient at all stages of the food chain, but are most reliable and productive under a narrow set of environmental interactions. For example, wheat populations that thrive under conditions of high fertility where weeds, pests and diseases are restricted have a high proportion of seminal roots and a single, short and strong stem with few small and erect leaves (Donald 1968). Furthermore, by continually restricting genetic variability, the pedigree line breeding approach has narrowed the genetic base of many of our crops. In response to this situation, Simmonds (1993) and Allard \& Hansche (1964) called for mass reservoirs of genetic variability as supplements to conventional breeding to help broaden the genetic base of crops and as a means for dynamic conservation of genes and genotypes.

Among inbred cereals, development of the composite cross approach arose out of a concern for this concentration on pedigree line breeding, limiting the exploitation of genetic resources. More recently, major questions have arisen concerning the economic, social and environmental costs associated with high input production. As a result, government policies are now directed frequently towards more sustainable approaches to crop production. Where these involve a significant reduction in inputs, the availability of nutrients is variable and weeds, pests and diseases are present. This requires an increase in appropriate genetic variation to maintain stability of output. In other words, there is a significant trade-off in crop output as control of the environment is reduced (Weiner 2003). The problem of maintaining output in variable environments has generated renewed interest in alternative approaches, including the possible use of composite cross populations (e.g. EU COST Action 860: www.cost860.dk). In this context it is appropriate to review the progress and value of composite cross population breeding through its potential to provide a comprehensive exploitation of the genetic resources used.

\section{COMPOSITE CROSS POPULATIONS}

Suneson's (1956) 'new' form of plant breeding suggested that it is important to recognize the value of evolutionary fitness. Suneson (1956) described a process of assembly of seed stocks with diverse evolutionary origins, recombination by hybridization, the bulking of $F_{1}$ progeny, and subsequent prolonged natural selection for mass sorting of the progeny in successive natural cropping environments. This breeding method depends upon the outcome of mass trials by artificial and natural selection acting upon a heterogeneous mixture of competing genotypes (Jain 1961). The success of such mass-propagated populations depends upon recombination and segregation over many generations, and the extent to which survival in such populations is positively correlated with agricultural value (Allard \& Hansche 1964). If these conditions are achieved then the mass-propagated populations may be a more appropriate method to pursue the potential of useful genes and gene combinations than the pedigree-line breeding approach; this is the case on the grounds of sampling alone which is improved by repeatedly harnessing recombination.

In the composite crosses described by Harlan \& Martin (1938) and Suneson (1956), a large number of barley varieties were intercrossed and all the hybrids were bulked together for propagation. Suneson (1969) registered nine barley composite crosses or gene pools as material for the generation of new varieties, valuable parent lines and material for the study of population genetics and breeding methods. One refinement to the idea of composite cross populations was the introduction of male sterility genes into the composite populations to produce hybrid seed beyond the $\mathrm{F}_{2}$ generation (Suneson 1951).

Suneson (1956) compared the performance of Atlas, a leading variety at the time, over 18 years of testing (1937-55) with composite cross populations, mostly under conditions described as maximum soil fertility. He found that Atlas was more variable in yield with a coefficient of variability nearly twice as high as one of the composite cross populations (C.C. II). Furthermore, in 1955, generation $\mathrm{F}_{29}$ of C.C. II offered a mean yield advantage of $19 \%$ over Atlas at three locations. In the same year, C.C. V $\left(\mathrm{F}_{15}\right)$, C.C. XII $\left(\mathrm{F}_{14}\right)$ and C.C. XIV $\left(\mathrm{F}_{12}\right)$ had yields similar to Atlas. By $F_{26}$ C.C. II was outyielded by C.C. XII, a composite derived from intercrossing 26 parents and backcrossing their progenies to the $F_{1}$ of Atlas and another barley variety 'Vaughn'. This gene pool also offered greater heterozygosity, smoother awns and whiter aleurone than other composite crosses of barley (Suneson 1969). One barley composite cross population (C.C. XIV), derived from intercrossing 9 cultivars, also incorporated alleles for male sterility (Suneson 1951); its evolutionary growth rate (measured as rate of increase in yield) appeared to benefit from the presence of male-sterility (Suneson 1956). Suneson (1956) also suggested that, with barley, 15 generations of natural selection seemed sufficient to develop composites that have improved agronomic fitness compared with the parent varieties.

The barley composite crosses provided material for a number of further studies. C.C. II was assessed by Hockett et al. (1983) under diverse production environments. They found that the composite cross populations outyielded test cultivars at two sites but the test cultivars outyielded the C.C. II populations at a third site. Hockett et al. report that the composite cross populations were generally lodging and disease susceptible and they were unable to perform in highly productive environments. Moreover, they suggested that the release of an advanced generation of C.C. 
II as a heterogeneous cultivar was not advisable because the yield level was not high enough and there was no marked increase in stability. However, they were more hopeful that individual lines derived from advanced generations of C.C. II could be evaluated as potential breeding materials and possibly as cultivars. They were convinced that composite-cross population development should act as a complement to other breeding methods. Soliman \& Allard (1991) also suggest that the yield level of C.C. II at later generations was not high enough to warrant release as a heterogeneous cultivar. Again, Soliman \& Allard suggest that individual lines derived from the latest generations of the composite crosses should be evaluated as potential breeding materials and cultivars for low-yielding environments.

Composite cross populations have also been studied in other cereal species, most notably in wheat. Wheat is a difficult species in which to utilize heterosis, due mainly to the problems of hybrid seed production in this homozygous inbreeding species. Nevertheless, Qualset (1968) reported $\mathrm{F}_{2}$ generation wheats outperforming the yield of parent stands by up to $26 \%$ under low yield conditions. However, Qualset also found that mixtures of homozygotes had a more stable performance than $F_{2}$ composite cross populations. Qualset suggests that wheat evolved primarily as mixtures of homozygotes rather than through heterogeneity obtained by high levels of heterozygosity, which might suggest that the heterozygosity of an $\mathrm{F}_{2}$ population is not optimum for high stability. Thomas et al. (1991) also examined composite crosses of wheat and reported yield improvements of a composite population of wheat of more than $15 \%$ over the mean of the parents in pure stands.

\section{PLANT-PLANT INTERACTIONS IN HETEROGENEOUS POPULATIONS}

Jain (1961) points out that with composite cross populations it is the direction of the correlation between the agronomic productivity of a genotype and its competitive ability that is important. For example, mixtures of varieties can provide an indication of the important factors for understanding plant-plant interactions in other heterogeneous populations. In this way, Sakai (1961) found that there is not necessarily a correlation between yield in pure stands and competitive ability in mixtures. Similarly, Clay \& Allard (1969) in studying mixtures of barley varieties suggest that it is too much to expect that varieties selected for high yielding ability in pure stands would have precisely the biological properties necessary for favourable interaction in heterogeneous populations.

Indeed, the competitive abilities of genotypes in heterogeneous populations are biologically complex. Blijenberg \& Sneep (1975) and Baker \& Briggs (1984) found that yield in monoculture of eight barley varieties appeared to be in agreement with their competitive ability in a variety mixture over 6 successive years. However, Rao \& Prasad (1984) and Khalifa \& Qualset (1974) found that competitive ability of wheat varieties in mixtures was conferred by plant height, not high yielding ability. Early \& Qualset (1971) found that competition affecting yield in mixtures of barley varieties was due to a decreased number of spikes per unit area and they suggest that this was due to competition at the time of tillering. Furthermore, Edwards \& Allard (1963) showed that competition between barley varieties was not associated with competition for light, but rather that it was due to competition principally for nutrients and moisture (Hartmann \& Allard 1964). The complexity of competitive ability in mixtures is complicated further since it must be dependent on the density of sowing, see Chapman et al. (1969), Weiner et al. (2001). Plant-plant interactions are affected by the availability of resources, with the indication that the advantage of heterogeneous cereal populations increases as the environment becomes more stressful (Frey \& Maldonado 1967).

The competitive interactions in heterogeneous populations are complex and dependent on a number of dynamic environmental factors. Where the conditions are sub-optimal for performance in pure stands, or where the impact of inter-genotypic competition is less than that of intra-genotypic competition on characters with some agronomic importance, then variety mixtures or heterogeneous populations may offer enhanced performance above pure stands. It seems that the advantages to heterogeneous populations are most likely to occur when plants are stressed by the availability of nutrients and water. A further factor is often disease (Finckh et al. 2000).

\section{PLANT-PATHOGEN INTERACTIONS IN HETEROGENEOUS POPULATIONS}

The interaction between the crop and plant pathogens is amongst the more important of the biotic interactions in crop populations. Again, variety mixtures provide indications of the complexity of performance of heterogeneous crop populations against pathogens. Most studies regarding the effects of host mixtures on disease have been with specialized, polycyclic, foliar pathogens of small grains, primarily rusts (Puccinia spp.) and powdery mildews (Blumeria [=Erysiphe $]$ graminis) (Mundt 2002). Variety mixtures can restrict these diseases by increasing the distance between susceptible plants, by resistant plants acting as barriers and by resistance reactions induced by avirulent spores to prevent or delay infection by adjacent virulent spores (see Finckh \& Wolfe 1998; Garrett \& Mundt 1999). Mixtures of 
barley varieties were used in the German Democratic Republic during the 1980s to restrict powdery mildew (caused by Erysiphe graminis). Such mixtures eventually occupied 0.92 of the spring barley area, which led to a decline in the national severity of the disease from $0 \cdot 50$ to $0 \cdot 10$ (Wolfe et al. 1987). Another example of mixtures being deployed across a large scale to restrict disease is in China, where mixtures of rice varieties reduced blast (caused by Magnaporthe grisea) on susceptible glutinous rice cultivars by an average of $94 \%$ (Zhu et al. 2000). We can expect similar mechanisms to operate in composite cross populations to restrict development of polycyclic fungal air-borne disease. Significant restraint of this form of environmental stress should result in increased productivity of the populations relative to pure stands, as observed for mixtures.

The deployment of highly heterogeneous populations as crop material would also have implications for the evolution of pathogen populations. Certainly any given resistance gene in a heterogeneous population will have less exposure to that pathogen population than if the same gene were deployed in monoculture of the same total crop area. It is more difficult to predict whether or not the effectiveness of a given number of resistance genes will be more durable deployed in a mixture as compared with the same number of genes deployed sequentially in monoculture or combined into a single host (Mundt 2002). The complexity of understanding selection of pathogen populations in heterogeneous hosts in different cropping systems is underlined by Mundt (2002). For example, he emphasizes that considering static costs of virulence alone is not sufficient in models for such pathogen evolution. It is possible that heterogeneous populations in the form of mixtures do slow the emergence of complex virulences and thereby improve the durability of host resistance (also see Barrett \& Wolfe 1980; Chin \& Wolfe 1984; H. J. Schaerer, pers. comm.). Heterogeneous populations in the form of composite cross populations may have the added advantage of more complex changes in resistance gene frequencies from season to season.

Alexander et al. (1986) illustrate how pathogen numbers have the potential to affect the genetic composition of host populations and how changes in the genetic composition of the host population can, in turn, affect both host and pathogen numbers. Hence, the outcome of competitive interactions among plants in heterogeneous populations may affect the durability of resistance to plant pathogens and the maintenance of heterogeneity for disease resistance. For instance, Chilvers \& Brittain (1972) present a simple model to explain the coexistence of plant genotypes in heterogeneous populations mediated in a frequency dependent manner by hostspecific pathogens. If two host types are attacked by two pathogen types and disease severity is positively correlated with host density, then there should be oscillations around equilibrium for host frequencies. However, this can only be the case if the competitive abilities of the hosts are similar under other environmental interactions. Paul \& Ayres $(1986,1990)$ also indicate the importance of different densities, proportions and nutrients in determining the outcome of competition among genotypes when affected by disease. Brunet \& Mundt (2000) showed that the rust fungus on wheat genotypes was unable to reverse the relative ranking of the two genotypes caused by competition and create the negative frequency dependence on both genotypes in a mixture that is required for the maintenance of genetic polymorphism for disease resistance. However, that does not preclude the possibility that competition may maintain polymorphism for other resistance gene/ pathogen population interactions, especially where there is a greater degree of heterogeneity in crop populations and those populations have a degree of outcrossing.

In barley, Jackson et al. (1982) showed that four different generations of barley C.C. V differed in resistance against Rhynchosporium secalis. Indeed, they take the presence of many different types of families, including large numbers of segregating families, to show that significant variability in disease resistance is maintained in the composite cross. Furthermore, they suggest that the appearance, disappearance, and reappearance of different family types from generation to generation seems to represent dynamic adaptable responses to a variable and shifting pathogen population. Allard (1990) found self-regulation between genes in composite cross populations of barley and genes in $R$. secalis populations. Saghai-Maroof et al. (1983) working with barley C.C. II found that the frequency of families resistant to Helminthosporium teres, Erysiphe graminis and Rhynchosporium secalis increased from early to later generations. However, it is not clear to what extent changes in these characters are due to hitchhiking with other traits that confer selective advantage. Webster et al. (1986) suggest that patterns of change in C.C. II indicate that selection favoured resistance alleles in seasons when disease was prevalent but that resistance alleles were detrimental to reproductive capacity in seasons that were unfavourable to disease.

Danquah \& Barrett $(2002 a, b)$ argue, from evidence from hordein analysis and tests of reactions to mildew isolates, that selection for Mla1 in Cambridge (UK) was the predominant evolutionary force in a composite cross of barley. They suggest therefore, that although the population could be a useful source of breeding material, it may be a risky method of conserving germplasm. Ibrahim \& Barrett (1991) found that natural infection by powdery mildew of 
barley led to an increase in the frequency of barley genotypes resistant to one or more common pathogen genotypes and they suggest that this loss of diversity would preclude the use of composite crosses for longterm conservation of total genetic diversity. However, De Smet et al. (1985) found increasing levels of resistance in composite cross populations of barley to Erysiphe graminis irrespective of the selection pressure applied by the pathogen, suggesting that associations with gene complexes other than mildew resistance explain the increases in resistance.

The complexity of population dynamics in composite cross populations illustrates the potential complexity of changes through time in these populations. Any changes will be related to the power of selection pressures, which in turn must be related to characteristics of the production system itself (man influenced or not). So, when Danquah \& Barrett (2002c) argue that selection for Mla1 in Cambridge (UK) has been the predominant evolutionary force in a composite cross of barley, this is perhaps as great a comment on the production system as on the crop population itself.

Plant-pathogen and plant-plant-pathogen interactions in composite cross populations illustrate two principles. Firstly, there is the complexity of natural selection in agricultural systems, even where gene-forgene (Flor 1955) interactions between plant resistance and pathogen virulence seem to be prevalent with a high degree of disease severity. This indicates that composite cross populations may provide useful breeding material for deployment in agricultural systems which are unpredictable in terms of dynamic selection pressures, within and between seasons. Second, composite crosses may also provide useful breeding material where there may be important genetic, ecological and epidemiological interactions among characters that may be overlooked by artificial selection, but not by natural selection. However, the use of composite crosses as a means of conserving genotypes may only be appropriate in systems where loss of diversity due to a few consistent, powerful selection pressures are not overwhelming. Improved conservation of genetic diversity may be achieved by maintaining diversity in low input environments or utilizing sites contrasting in selection pressures and alternating composite cross generations among them. Indeed, Paillard et al. (2000) recommend growing composite crosses on sites contrasting in powerful selection pressures to allow genetic drift in some populations and selection in others, as an effective tool for maintaining the diversity of genes for specific resistance to pathogen populations. The heritability of characters in the different environments will also affect the usefulness of diversity in those sites for conserving genetic diversity.

Encouraging recurrent selection in inbreeding species, perhaps utilizing naturally occurring male sterility, will also aid in the usefulness of composite crosses to conserve diversity. Indeed, plant-pathogen and plant-plant-pathogen interactions in composite crosses illustrate the observations of Allard (1990) that it is not sufficient simply to have superior alleles in breeding stocks; such alleles must be assembled into superior combinations at the intra-locus level and also at the inter-locus level to exploit favourable interactions. To do this, large numbers of cycles of segregation and recombination are required and population sizes must be large to guarantee production of the most useful genotypes.

\section{AGRONOMIC PERFORMANCE OF COMPOSITE CROSS POPULATIONS}

Natural selection in composite crosses of barley selected favourably for increased grain yield, but affected maturity, plant height and relationships among traits unfavourably (Patel et al. 1987). Patel et al. recommend the use of artificial selection to counteract undesirable changes in traits, other than yield, of agronomic importance. Jain \& Qualset (1975) summarized the nature of selective forces in composite crosses of barley. Interestingly, they suggest that directional selection occurred for seed yield per plant or per plot, with a slow and steady increase after an initial phase of no change, and stabilizing selection occurred for days to heading, seed size, spike length and spike density. Overall phenotypic and genetic variability was said to show varying rates of decrease in different populations due to a complex of selective forces. Hence, unless natural selection favours genotypes which possess agronomic promise then composite populations themselves will not be useful for commercial production and intervention by artificial selection may be required.

Furthermore, Mak \& Harvey (1982) suggest that one way to tackle the slowness of natural selection in deriving characters of agronomic importance and to deal with undesirable shifts in some characters, is to adopt artificial selection. For instance, Mak \& Harvey (1982) found shifts towards later maturity, increasing tallness and a small kernel size in studies of a composite cross population of barley. They suggest that these problems may be overcome by mowing off the tall heads before harvest and by sieving for larger seeds. However, Allard \& Hansche (1964) suggest that yield of broadly based populations, maintained without conscious selection improves rapidly and within 10 to 15 generations after synthesis. This suggests that natural selection identifies agronomically superior types such that they make up greater and greater proportions of populations in later generations. Danquah \& Barrett $(2002 c)$ confirmed that natural selection in advanced generations of a composite cross of barley may produce populations that are well suited to unpredictable and stressed 
environments. Hence, the problem of when and how artificial selection should be allowed in composite cross breeding programmes is impossible to address. But the answers are related to the objectives of any one composite cross programme: as a dynamic gene pool, to provide a heterogeneous crop, or to conserve germplasm resources. Furthermore, decisions about artificial selection must also be related to the type and power of natural selection; this recognizes that maximum response to selection is expected when material is advanced under directional selection pressure in a single, unchanging environment.

As indicated above, it must be important to allow natural or artificial selection to operate under the conditions for which wide adaptation is required. St-Pierre et al. (1967) support the importance of the practical use of genotype-environment interactions for obtaining varieties with wider adaptation and for increasing the efficiency of selection. However, Choo et al. (1980) failed to demonstrate that alternation between sites broadened adaptation in composite populations. Patel et al. (1987) also report the same, as there was no advantage gained from alternating composites across diverse locations, probably because of the influence of disruptive selection. Hensleigh et al. (1992) point out that the decision of plant breeders on the productivity level of the selection and testing environment becomes more critical as unpredictability and variability increase. Hence, the identification of the best environment for selection, where target environments are inherently heterogeneous, points to using alternative generations of heterogeneous material under suitably heterogeneous conditions (Ceccarelli 1996). Zavala-Garcia et al. (1992) confirm this position by suggesting that yield information representing the range of environments in the target area should be involved in the definition of the selection criteria to achieve gain in the selection of genotypes for unpredictable environments.

Rasmusson et al. (1967) found an increase in yield of a composite cross population of barley of an average of $9.5 \%$ per year under stressed conditions. Similarly, Hockett et al. (1983) found that natural selection under diverse environments delivered composite crosses that were able to outyield check cultivars in many environments. Allard (1961) found that niche differentiation of lima bean populations increased the stability in yield performance of those populations compared to pure stands. He suggests that populations and mixtures appear to be insured against stressful environments but that the same forces that encourage this stability do not necessarily endow mixtures with higher than average productive capacity. Qualset (1968) suggests that it should be possible to use advanced generations of inter-varietal crosses to provide improved yield stability in low input environments. This is consistent with the conclusions of Lohani (1975) who found that genotypes from barley composite cross $\mathrm{V}$ that had specific adaptation were at a disadvantage and were gradually eliminated from populations.

\section{COMPOSITE CROSS BREEDING IN LOW INPUT ENVIRONMENTS}

Grain yields in wheat have improved greatly over the last 50 years. Austin et al. (1980) explain that much of this improvement has been due to adjusting the harvest index in favour of grain yield over grain and straw yield. Genetic improvements have also contributed to this increase by increasing lodging and disease resistance, permitting the use of increased amounts of nitrogen fertilizer. Foulkes et al. (1998) found a negative relationship between year of entry of cultivars and the offtake of nitrogen in grain, suggesting that genotypes produced from the mid1970 s to the late 1980 s were progressively less efficient at acquiring soil nitrogen. As Calderini et al. (1997) explain, biomass at anthesis tends to be lower in recently released cultivars than in older materials, caused by differences in the length of developmental phases among cultivars rather than by changes in the architecture of the canopies. Hence it may be that more recent cultivars are more poorly adapted to soil nitrogen uptake over winter and in early spring. However, Le Gouis et al. (2000) found that some modern wheat varieties performed well in conditions where nitrogen was comparatively low. Again, Le Gouis et al. (2000) point to cultivar development timing as being an important interaction with the availability of nitrogen in the soil. Cultivar development stage is also important in dealing with other resource stresses, and flowering stage may be important in affecting drought resistance (Foulkes et al. 2001).

Ceccarelli (1996) argues that because breeding is mostly conducted in the presence of high inputs, it has systematically missed the opportunity to exploit genetic differences at low levels of inputs. However, there are arguments that selection under high fertility conditions may also be appropriate for identifying traits and varieties that may have wide adaptation under low input conditions (see Rosielle \& Hamblin 1981; Atlin \& Frey 1989; Zavala-Garcia et al. 1992). Regardless of whether or not it is better to select pure lines in low or high input conditions, it does seem that heterogeneity for development stages, for disease resistances and for improved plant-plant interactions under low fertility conditions, is one way of dealing with the stress environments provided by low input agricultural systems. This begins to explain the stability of yields reported for mixtures of varieties and populations and even for improvements in grain quality for mixtures of cultivars when no nitrogen is applied (Sarandon \& Sarandon 1995). The predictability of abiotic and biotic stresses in different 
low input systems is poor; it is therefore difficult to choose/select pure line varieties that will perform best under all low input conditions. This indicates the advantage of the composite cross breeding method both as a means of generating new varieties and of providing stable crop populations for low input agricultural systems. Also, composite cross population breeding is an appropriate method for locally based breeding programmes. Ceccarelli (1996) suggests that locally based breeding programmes are the best avenue to achieve a sustainable increase of agricultural production in low input agricultural systems.

Crop breeding through composite cross crop populations recognizes the importance of a Darwinian view which links, seamlessly, ecological and evolutionary processes with ecosystem functioning; this is a view that may prove valuable in developing sustainable and efficient agricultural practices (see Tilman 1999). Simmonds (1993) recognizes the possible value of composite crosses as insurance against what he terms the politico-bureaucratic aspects of plant breeding and the maintenance of genetic variability. However, the exploitation of composite cross crop populations requires shifts in legal and administrative frameworks of variety management and certainly, in the case of low input systems, this means the encouragement of alternative markets that do not drive so readily towards the industrialization of agriculture.

It is also worthy of note that molecular markers are now a common tool in breeding programmes. They provide a means of understanding the genetic control of traits, they are useful as a criterion for selecting parents and as a way of following genes of interest in segregating populations. Molecular markers have already been used in composite cross populations to understand evolutionary pressures in those populations (see Enjalbert et al. 1999a,b). Microsatellite markers can also be used to determine the relative proportions of different cultivars in heterogeneous crop populations, aiding an understanding of the effects of competition on the population dynamics within heterogeneous crops. All these factors may help in speeding up the slow process of breeding from composite cross populations and for developing heterogeneous crop populations by elucidating the relationships between traits and population dynamics.

\section{CONCLUSIONS}

The usefulness of composite cross populations as dynamic gene pools or to conserve germplasm resources is not clear. Both of these aims are dependent upon the choice of parent lines for initial crossing, the occurrence of recurrent recombination and the type, number and management of environments for selection.
However, the literature indicates that composite cross populations may be an efficient method for providing useful heterogeneous crops and for selecting pure lines particularly for low input systems. This is because composite cross populations respond dynamically to complex natural and artificial selection from abiotic and biotic stresses which can generate crop populations superior to pure stands of the parent lines. Indeed, the agronomic superiority of composite cross populations is most likely to be revealed under stress conditions. Developments in molecular marker technology should help in the rapid production of effective composite populations and in improving the understanding of the dynamics and genetics of such populations.

If populations are to be used as heterogeneous crops, it is difficult to predict whether the best initial gains can be made by exposing the populations to markedly different environments in alternating generations (e.g. high fertility $v$. low inputs), or to continuous selection in related environments. The answer is probably dependent upon the environments used and the genetic resource available. In practice, it may be better to release population samples to individual farmers to encourage local selection from an early stage (Ceccarelli 1996). This could lead to 'island' effects with significant levels of specific locality adaptation which may have value in terms of both stability and local market opportunity.

Similarly, there is no consensus about how to monitor performance of the populations over generations. Three methods have been used. The first is to compare population performance against all of the component parents grown as pure stands. This approach is important for determining the rate and degree of divergence from the parental phenotypes. However, it requires considerable space and is of limited practical interest since the populations are genotypically different from the parents. A second method is to compare population performance against one or a few standards. Though simple in practice, this may produce misleading results because the few controls may be (unpredictably) effective or ineffective in certain environments. The third possibility is to compare population performance against the physical mixture of the parents used in the composites. This is efficient in terms of field space required and explores further the fundamental question raised by Qualset (1968) for wheat - are mixtures of homozygous lines better than heterozygous populations from an evolutionary point of view?

It is also unclear from the literature whether artificial, mass selection can accelerate population evolution in desired directions or not. In this context, a pragmatic view may be best - for example, if populations tend to evolve to heights that are impractical and likely to lead to lodging, then removal of talls 
may be desirable, or, if seed-borne disease appears to be common, then selection against small grain may be advantageous.

There are also questions concerning the end-use of the material produced from composite cross populations. However, evidence from the literature suggests that the end products from both populations and variety mixtures can be more stable in terms of both yield and quality.

Long-term concentration on pedigree line breeding has led to the development of a complex legal and administrative framework for the introduction, use and protection of varieties, which limits the genetic response to variable environments. In this context, analysis of the composite cross population approach can provide a fundamental contribution to debates about wider sustainability issues, including aspects of the ownership and development of future genetic resources. Against the perceived problems of utilizing wheat populations, it is also important to point out that procedures are well defined and accepted for dealing with rye where populations account for probably more than half of European production (Miedaner, pers. comm.).

\section{REFERENCES}

Alexander, H. M., Roelfs, A. P. \& Cobbs, G. (1986). Effects of disease and plant competition on yield in monocultures and mixtures of two wheat cultivars. Plant Pathology 35, 457-465.

Allard, R. W. (1961). Relationship between genetic diversity and consistency of performance in different environments. Crop Science 1, 127-133.

Allard, R. W. (1990). The genetics of host-pathogen coevolution: implications for genetic resource conservation. The Journal of Heredity 81, 1-6.

Allard, R. W. \& Hansche, P. E. (1964). Some parameters of population variability and their implications in plant breeding. Advances in Agronomy 16, 281-325.

Atlin, G. N. \& Frey, K. J. (1989). Predicting the relative effectiveness of direct versus indirect selection for oat yield in three types of stress environments. Euphytica 44, 137-142.

Austin, R. B., Bingham, J., Blackwell, R. D., Evans, L. T., Ford, M. A., Morgan, C. L. \& Taylor, M. (1980). Genetic improvements in winter wheat yields since 1900 and associated physiological changes. Journal of Agricultural Science, Cambridge 94, 675-689.

BAKer, R. J. \& Briggs, K. G. (1984). Comparison of grain yield of uniblends and biblends of 10 spring barley cultivars. Crop Science 24, 85-87.

Barrett, J. A. \& Wolfe, M. S. (1980). Pathogen response to host resistance and its implications in breeding programmes. European Mediterranean. Plant Protection Organisation Bulletin 10, 341-47.

Biffen, R. H. (1905). Mendel's laws of inheritance and wheat breeding. Journal of Agricultural Science, Cambridge 1, 4- 48.

Blijenberg, J. G. \& Sneep, J. (1975) Natural selection in a mixture of eight barley varieties, grown in six successive years. 1. Competition between the varieties. Euphytica 24, 305-315.

Brunet, J. \& Mundt, C. C. (2000). Combined effects of disease and competition on plant fitness. Canadian Journal of Botany 78, 646-654.

Butler, E. J. (1905). The bearing of Mendelism on the susceptibility of wheat to rust. Journal of Agricultural Science, Cambridge 1, 361-363.

Calderini, D. F., Dreccer, M. F. \& Slafer, G. A. (1997). Consequences of breeding on biomass, radiation interception and radiation-use efficiency in wheat. Field Crops Research 52, 271-281.
Ceccarelli, S. (1996). Adaptation to low/high input cultivation. Euphytica 92, 203-214.

Chapman, S. R., Allard, R. W. \& Adams, J. (1969). Effect of planting rate and genotypic frequency on yield and seed size in mixtures of two wheat varieties. Crop Science 9, 575-577.

Chilvers, G. A. \& Brittain, E. G. (1972). Plant competition mediated by host-specific parasites. A simple model. Australian Journal of Biological Sciences 25, 749-756.

Chin, K. M. \& Wolfe, M. S. (1984). Selection on Erysiphe graminis in pure and mixed stands of barley. Plant Pathology 33, 535-546.

Choo, T. M., Klinck, H. R. \& St-Pierre, C. A. (1980). The effect of location on natural selection in bulk populations of barley (Hordeum vulgare L.). II Quantitative traits. Canadian Journal of Botany 60, 41-47.

Clay, R. E. \& Allard, R. W. (1969). A comparison of the performance of homogenous and heterogenous barley populations. Crop Science 9, 407-412.

Danquah, E. Y. \& Barrett, J. A. (2002a). Evidence of natural selection for disease resistance in Composite Cross Five (CCV) of barley. Genetica 115, 195-203.

Danquah, E. Y. \& Barrett, J. A. (2002b). Hordein variation and reaction to powdery mildew in composite cross XLII of barley. Genetica 114, 81-87.

Danquah, E. Y. \& Barrett, J. A. (2002c). Grain yield in composite cross five of barley: effects of natural selection. Journal of Agricultural Science, Cambridge 138, 171-176.

Darwin, C. (1859) On The Origin Of Species By Means Of Natural Selection. J. Murray, London.

De Smet, G. M. W., Scharen, A. L. \& Hockett, E. A. (1985). Conservation of powdery mildew resistance genes in three composite cross populations of barley. Euphytica 34, 265-272.

Donald, C. M. (1968). The design of a wheat ideotype. In Proceedings of the Third International Wheat Genetics Symposium (Eds K. W. Finlay \& K. W. Shephard), pp. 377-387. Canberra, Australia: Australian Academy of Sciences.

Early, H. L. \& Qualset, C. O. (1971). Complementary competition in cultivated barley (Hordeum vulgare L.). Euphytica 20, 400-409.

Edwards, K. J. R. \& Allard, R. W. (1963). The influence of light intensity on competitive ability. The American Naturalist 97, 243-248. 
Enjalbert, J., Boeuf, C., Belcram, H. \& Leroy, P. (1999a). Use of multiparental inbred populations to determine allelic relationships of molecular markers. Plant Breeding 118, 88-90.

Enjalbert, J., Goldringer, I., Paillard, S. \& Brabant, P. $(1999 b)$. Molecular markers to study genetic drift and selection in wheat populations. Journal of Experimental Botany 50, 283-290.

FinckH, M. R. \& Wolfe, M. S. (1998). Diversification strategies. In The Epidemiology of Plant Diseases (Ed. D. G. Jones), pp. 231-259. London: Chapman and Hall.

Finckh, M. R., Gacek, E. S., Goyeau, H., Lannou, Ch., Merz, U., Mundt, C., Munk, L., Nadziak, J., Newton, A. C., de Vallavieille-Pope, C. \& Wolfe, M. S. (2000). Cereal variety and species mixtures in practice, with emphasis on disease resistance. Agronomie 20, 813-837.

FLOR, H. H. (1955). Host-parasite interaction in flax rust - its genetics and other implications. Phytopathology 45, 680-685.

Foulkes, M. J., Sylvester-Bradley, R. \& Scott, R. K. (1998). Evidence for differences between winter wheat cultivars in acquisition of soil mineral nitrogen and uptake and utilization of applied fertilizer nitrogen. Journal of Agricultural Science, Cambridge 130, 29-44.

Foulkes, M. J., Scott, R. K. \& Sylvester-Bradley, R. (2001). The ability of wheat cultivars to withstand drought in UK conditions: resource capture. Journal of Agricultural Science, Cambridge 137, 1-16.

Frey, K. J. \& MALdonado, U. (1967). Relative productivity of homogenous and heterogeneous oat cultivars in optimum and suboptimum environments. Crop Science 7, $532-535$.

Garrett, K. A. \& Mundt, C. C. (1999). Epidemiology in mixed host populations. Phytopathology 89, 984-990.

Harlan, H. V. \& Martini, M. L. (1938). The effect of natural selection in a mixture of barley varieties. Journal of Agricultural Research 57, 189-199.

Hartmann, R. W. \& Allard, R. W. (1964). Effect of nutrient and moisture levels on competitive ability in barley (Hordeum vulgare L.). Crop Science 4, 424-426.

Hensleigh, P. F., Blake, T. K. \& Welty, L. E. (1992). Natural selection on winter barley composite cross XXVI affects winter survival and associated traits. Crop Science 32, 57-62.

Hockett, E. A., Eslick, R. F., Qualset, C. O., Dubbs, A. L. \& Stewart, V. R. (1983). Effects of natural selection in advanced generations of Barley composite cross II. Crop Science 23, 752-756.

Ibrahim, K. M. \& Barrett, J. A. (1991). Evolution of mildew resistance in a hybrid bulk population of barley. Heredity 67, 247-256.

Jackson, L. F., Webster, R. K., Allard, R. W. \& Kahler, A. L. (1982). Genetic analysis of changes in scald resistance in barley composite cross V. Phytopathology $\mathbf{7 2}$, 1069-1072.

JAIN, S. K. (1961). Studies on the breeding of self-pollinating cereals. The composite cross bulk population method. Euphytica 10, 315-324.

JaIn, S. K. \& Qualset, C. O. (1975). New development in the evaluation and theory of bulk populations. In Barley Genetics III. Proceedings of the Third International Barley Genetics Symposium (Ed. H. Gaul), pp. 739-749. Munich, Germany: Verlag Karl Theimig.
Khalifa, M. A. \& Qualset, C. O. (1974). Intergenotypic competition between tall and dwarf wheats. I. In mechanical mixtures. Crop Science 14, 795-799.

Le Gouis, J., Beghin, D., Heumez, E. \& Pluchard, P. (2000). Genetic differences for nitrogen uptake and nitrogen utilization efficiencies in winter wheat. European Journal of Agronomy 12, 163-173.

LOHANI, S. N. (1975). Influence of natural selection on yield and adaptation of composite cross population of barley. In Barley Genetics III. Proceedings of the Third International Barley Genetics Symposium (Ed. H. Gaul), pp. 730-738. Munich, Germany: Verlag Karl Theimig.

MaK, C. \& Harvey, B. L. (1982). Exploitable genetic variation in composite bulk populations of barley. Euphytica 31, 85-92.

Mundt, C. C. (2002). Use of multiline cultivars and cultivar mixtures for disease management. Annual Review of Phytopathology 40, 381-410.

Paillard, S., Goldringer, I., Enjalbert, J., Doussinault, G., De Vallavieille-Pope, C. \& Brabant, P. (2000). Evolution of resistance against powdery mildew in winter wheat populations conducted under dynamic management. 1. Is specific seedling resistance selected? Theoretical and Applied Genetics 101, 449-456.

Patel, J. D., Reinbergs, E., Mather, D. E., Choo, T. M. \& Sterling, J. D. E. (1987). Natural selection in a doublehaploid mixture and a composite cross of barley. Crop Science 27, 474-479.

Paul, N. D. \& Ayres, P. G. (1986). Interference between healthy and rusted groundsel (Senecio vulgaris L.) within mixed populations of different densities and proportions. New Phytologist 104, 257-269.

Paul, N. D. \& Ayers, P. G. (1990). Effects of interactions between nutrient supply and rust infection of Senecio vulgaris L. on competition with Capsella bursa-pastoris $\mathrm{L}$. Medic. New Phytologist 114, 667-674.

Qualset, C. O. (1968). Population structure and performance in wheat. In Barley Genetics III. Proceedings of the Third International Barley Genetics Symposium (Ed. H. Gaul), pp. 397. Munich, Germany: Verlag Karl Theimig.

RAO, B. R. R. \& PRASAD, R. (1984). Intergenotypic competition in mixed stands of spring wheat genotypes. Euphytica 33, 241-247.

Rasmusson, D. C., Beard, B. H. \& Johnson, F. K. (1967). Effect of natural selection on performance of a barley population. Crop Science 7, 543.

Rosielle, A. A. \& Hamblin, J. (1981). Theoretical aspects of selection for yield in stress and non-stress environments. Crop Science 21, 943-946.

Saghai Maroof, M. A., Webster, R. K. \& Allard, R. W. (1983). Evolution of resistance to scald, powdery mildew, and net blotch in barley composite cross II populations. Theoretical and Applied Genetics 66, 279-283.

SAKAI, K. I. (1961). Competitive ability in plants: its inheritance and some related problems. In Mechanisms in Biological Competition, Symposium of the Society of Experimental Biology No. 15 (Ed. F. L. Milthorpe), pp. 245-263. Cambridge: Cambridge University Press.

Sarandon, S. J. \& Sarandon, R. (1995). Mixture of cultivars: pilot field trial of an ecological alternative to improve production or quality of wheat (Triticum aestivum). Journal of Applied Ecology 32, 288-294.

Simmonds, N. W. (1962). Variability in crop plants, its use and conservation. Biological Reviews 37, 442-465. 
Simmonds, N. W. (1993). Introgression and incorporation. Strategies for the use of crop genetic resources. Biological Reviews 68, 539-562.

Soliman, K. M. \& Allard, R. W. (1991). Grain yield of composite cross populations of barley: Effects of natural selection. Crop Science 31, 705-708.

St-Pierre, C. A., Klinck, H. R. \& Gauthier, F. M. (1967). Early generation selection under different environments as it influences adaptation of barley. Canadian Journal of Plant Science 47, 507-517.

Suneson, C. A. (1951). Male-sterile facilitated synthetic hybrid barley. Agronomy Journal 43, 234-236.

SunEson, C. A. (1956). An evolutionary plant breeding method. Agronomy Journal 48, 188-191.

Suneson, C. A. (1969). Registration of germplasm; registration of barley composite crosses. Crop Science $\mathbf{9}$, 395-396.

Thomas, G., Rousset, M., Pichon, M., Trottet, M., Doussinault, G. \& Picard, E. (1991). Breeding methodology in wheat (Triticum aestivum L.). 1. Creation and study of a 16-parent artificial population. Agronomie 11, 359-368.

Tilman, D. (1999). Global environmental impacts of agricultural expansion: the need for sustainable and efficient practices. Proceedings of the National Academy of Sciences USA 96, 5995-6000.
Webster, R. K., Shaghai-Maroof, M. A. \& Allard, R. W. (1986). Evolutionary response of barley composite cross II to Rhynchosporium secalis analyzed by pathogenic complexity and by gene-by-race relationships. Phytopathology 76, 661-669.

Weiner, J. (2003). Ecology - the science of agriculture in the 21 st century. Journal of Agricultural Science, Cambridge 141, 371-377.

Weiner, J., Griepentrog, H.-W. \& Kristensen, L. (2001). Suppression of weeds by spring wheat (Triticum aestivum) increases with crop density and spatial uniformity. Journal of Applied Ecology 38, 784-790.

Wolfe, M. S., Minchin, P. N. \& Slater, S. E. (1987). Control of barley mildew by integrating the use of varietal resistance and seed-applied fungicides. In Integrated Crop Protection in Cereals (Ed. R. Cavalloro), pp. 229-236. Brussels: Commission of the European Community.

Zavala-Garcia, F., Bramel-Cox, P. J., Eastin, J. D., Witt, M. D. \& Andrews, D. J. (1992). Increasing the efficiency of crop selection for unpredictable environments. Crop Science 32, 51-57.

Zhu, Y., Chen, H., Fan, J., WAng, Y., Li, Y., Chen, J., FAN, J., Yang, S., Hu, L., Leung, H., Mew, T. W., Teng, P. S., WANG, Z. \& MundT, C. C. (2000). Genetic diversity and disease control in rice. Nature 406, 718-722. 